\title{
Exégesis de los delitos contra la familia en el Código Penal peruano
}

\section{Analysis of Crimes Against the Family in the Peruvian Criminal Code}

Javier Ysrael Momethiano Santiago* https://orcid.org/0000-0002-6009-1907 Yeniffer Stefani Ojeda Paravicino** https://orcid.org/0000-0002-6423-6464

http://dx.doi.org/10.21503/lex.v17i23.1673

* Abogado, magíster en Derecho Penal, egresado del Doctorado en Derecho de la Universidad Nacional Mayor de San Marcos (Lima, Perú)). Profesor de Derecho Penal especial de la EUPG - Universidad Nacional Federico Villarreal (Lima, Perú).

Correo electrónico: momethianoabogados@yahoo.es

** Abogada, magíster en Derecho Notarial y Registral por la Universidad Inca Garcilaso de la Vega (Lima, Perú). Abogada de la Dirección Ejecutiva Legal de la Universidad Alas Peruanas (Lima, Perú).

Correo electrónico: y_ojeda@uap.edu.pe

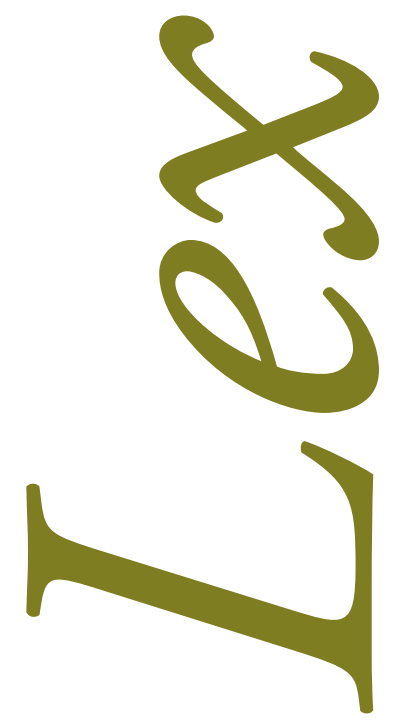




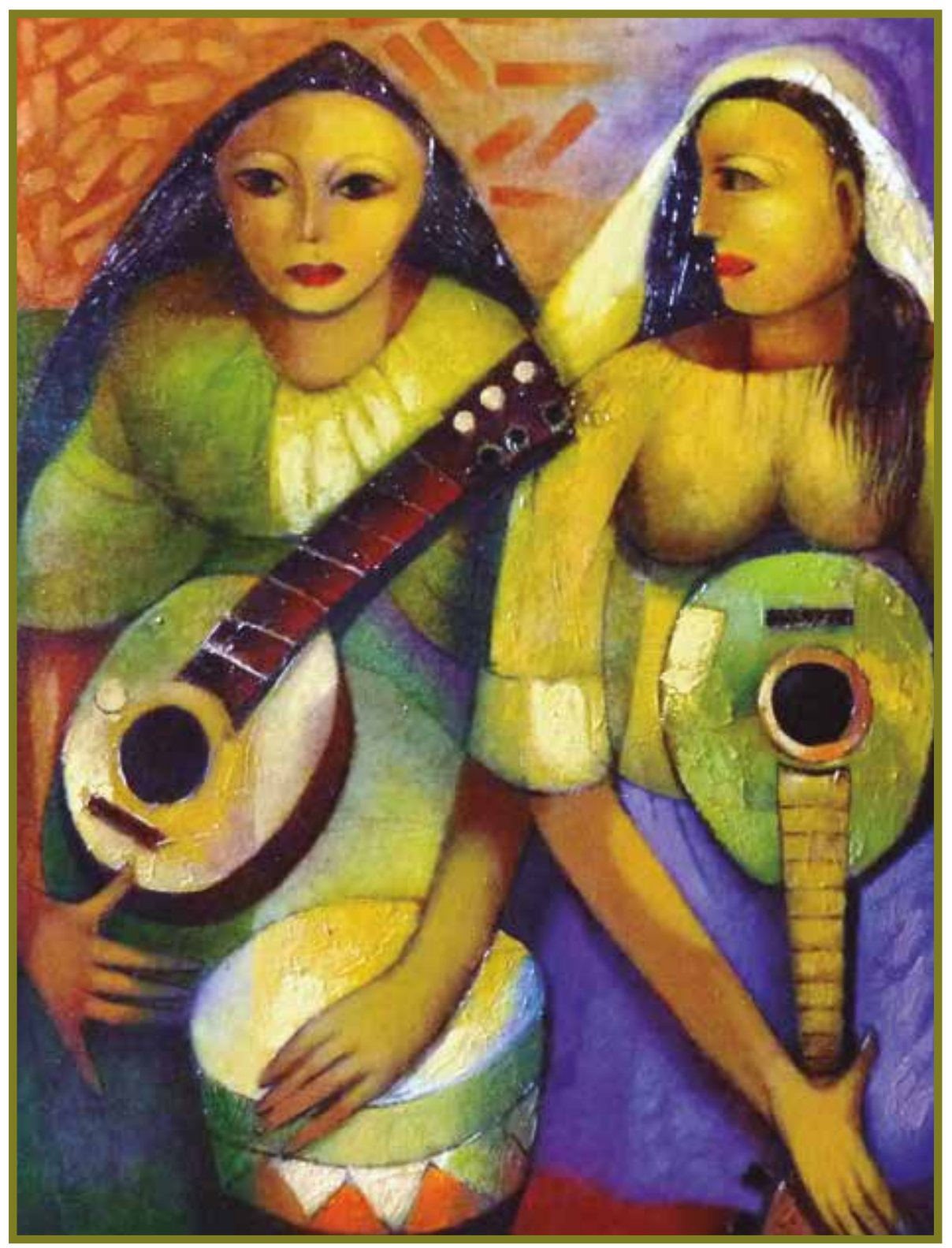

Mujeres y mandolina. Óleo.

Agustín Aquino Mejías (pintor peruano). 


\section{RESUMEN}

La dogmática penal referida a los delitos contra la familia nos permite realizar exégesis de las conductas prohibidas contenidas en los tipos penales que son merecedoras de sanción penal, pues en los matrimonios ilegales se tiene como bien jurídico tutelado la familia, protegiéndose específicamente, al matrimonio monogámico, así como a la madre, el padre y los hijos. También se salvaguardan en los ilícitos contra el estado civil (soltero, casado, viudo, o divorciado) los diferentes derechos, facultades u obligaciones que le atańen al sujeto. Finalmente, tratamos el polémico ilícito de omisión a la asistencia familiar, puesto que estamos de acuerdo con varios jurisconsultos en que la pena efectiva pone en riesgo a la familia del condenado respecto a su integridad, vida, y unidad.

Palabras clave: delitos contra la familia, matrimonios ilegales, omisión a la asistencia familiar.

\section{ABSTRACT}

Criminal dogmatics referring to crimes against the Family allows us to analyze the prohibited behavior defined as criminal offenses subject to criminal punishment, because in the case of illegal marriages the legal system aims to protect the family, and specifically, the monogamous marriage as well as the mother, the father and the children. It also protects the different rights, abilities and obligations concerning the subject in the case of illegal acts against the civil status (single, married, widowed or divorced).

At last, the author addresses the controversial offense of family neglect, as many law specialists maintain that the effective punishment jeopardizes the integrity, life and unity of the convicted person's family.

Key words: crimes against the family; illegal marriages; neglect of family assistance. 


\section{CONSIDERACIONES GENERALES}

La dogmática penal de la Parte Especial referido a los delitos contra la familia, permite examinar aquellas conductas recogidas en los tipos penales, que se estiman como merecedoras de sanción penal, es decir, no se pretende conocer el delito y la pena en abstracto sino en concreto, lo que no implica que el Libro Segundo del Código Penal sea independiente de la Parte General, pues existen principios comunes vinculados con cada figura delictiva. Para concretarnos al análisis particularizado de cada ilícito contenido en la Parte Especial del Código Penal, es necesario seguir el procedimiento siguiente:

- La descripción típica: Se señala el artículo del Código Penal, el dispositivo de la Ley Penal Especial (principio de legalidad).

- El bien jurídico tutelado: Se establece en el ilícito qué valor inmaterial del orden social (abstracto) es el que se protege (clasificación de los delitos en el Código Penal).

- El tipo objetivo: Se precisa quién o quiénes son los sujetos activos o pasivos del delito, y cuál es el comportamiento prohibido.

- El tipo subjetivo: Se ausculta el dolo o la culpa, y los elementos subjetivos del tipo.

- La antijuridicidad: Es el comportamiento opuesto al ordenamiento jurídico que lesiona o pone en peligro un bien jurídico tutelado.

- La responsabilidad: Comprende a la culpabilidad y prevención, ya que propone la vinculación de la dogmática jurídico penal con la finalidad político criminal.

- El tipo de perfecta realización: Se examina la consumación del hecho punible.

- El tipo de imperfecta realización: Se estudia si es admisible o no la tentativa.

- La condición objetiva de punibilidad: Es aquella circunstancia que se aparta del injusto culpable o aquella circunstancia que corresponde al injusto culpable, pero que se aleja de este, con el propósito de disminuir los requisitos objetivos y subjetivos de imputación. 
- La autoría y participación: Se analiza al autor inmediato, autor mediato o coautor; así como al instigador o cómplice en el hecho delictuoso.

- La circunstancia agravante: Es el incremento de la punibilidad, en razón a existir comportamientos prohibidos específicos o genéricos.

- El concurso: Es el modo en que aparece el delito en relación con la conducta y su resultado.

- Cuestiones procesales: Se aprecia la vía procesal penal y determinadas tramitaciones.

\section{MATRIMONIOS ILEGALES}

\section{II.1. Bigamia}

\section{II.1.1. Descripción típica}

Art. 139. El casado que contrae matrimonio será reprimido con pena privativa de libertad no menor de uno ni mayor de cuatro años.

Si respecto a su estado civil induce a error a la persona con quien contrae el nuevo matrimonio, la pena será privativa de libertad no menor de dos ni mayor de cinco años.

\section{II.1.2. Bien jurídico tutelado}

Es la familia, se protege tanto al matrimonio como institución social que se caracteriza por su unidad expresada en forma monogámica, ${ }^{12}$ como al grupo reducido de personas que la constituyen: la madre, el padre y los hijos, ${ }^{3}$ con exclusión de miembros ajenos a esta. Por su parte, Reyna Alfaro sostiene que se salvaguarda "la institución matrimonial monogámica como única institución lícita para modificar el estado civil a través del matrimonio", 4 en el delito de bigamia, pues cita para avalar su posición el trabajo publicado en 1988 del maestro Luis Alberto Bramont Arias, comentando el Código Penal de 1924 -quien sostenía que el "objeto específico de tutela penal es el interés del Estado de garantizar el orden jurídico familiar en cuanto particularmente se atiene al régimen monogámico, fundamento de nuestra sociedad" -5 pero sin considerar el bien jurídico tutelado familia ${ }^{6}$, como última postura del recordado maestro peruano, lo que determina que el sustento de Reyna Alfaro carece de toda objetividad. ${ }^{7}$

\footnotetext{
Eloy Momethiano Zumaeta y Max Mallqui Reynoso, Derecho de familia, tomo I (Lima: Editorial San Marcos, 2002 ), 50. Javier Rolando Peralta Andía, Derecho de familia en el Código Civil, cuarta edición (Lima: Idemsa, 2008), 119.

Marcial Rubio Correa, Para conocer la Constitución de 1993, tercera edición (Lima: Fondo Editorial de la Pontificia Universidad Católica del Perú, 2012), 54.

Francisco Muñoz Conde, Derecho penal. Parte especial (Valencia: Tirant lo Blanch, 1996), 254.

5 Citado por Luis Miguel Reyna Alfaro, Delitos contra la familia (Lima: Gaceta Jurídica, 2004), 23.

6 Luis Alberto Bramont Arias y Luis Alberto Bramont Arias Torres, Código Penal anotado, cuarta edición (Lima: Editorial San Marcos, 2001), 342.

7 Javier Ysrael Momethiano Santiago, Código Penal fundamentado (Lima: Editorial San Marcos, 2011), 186-187.
} 


\section{II.1.3. Tipo objetivo}

El sujeto activo es la persona casada (tipo especial propio), siendo posible que ambos contrayentes cometan bigamia. El sujeto pasivo es la colectividad y los afectados, como el cónyuge del matrimonio anterior o primigenio, así como de la persona soltera, viuda o divorciada que contrae nupcias, sin saber el estado civil de casado del sujeto activo.

La conducta típica consiste en que la persona casada -mediante matrimonio valido en territorio nacional o extranjero- contrae nupcias con persona distinta a la de su anterior o primer matrimonio. La nulidad del matrimonio anterior o primigenio excluye el tipo. Si la persona ya casada contrae matrimonio religioso con otro, estaremos frente una causa de atipicidad.

\section{II.1.4. Tipo subjetivo}

Es el dolo, y no se requiere elemento subjetivo diverso al dolo. El tipo se excluye por el error que debe desvanecer el principio de sospecha que se tiene sobre el auténtico estado civil del sujeto activo.

\section{II.1.5. Antijuridicidad}

Se entiende por antijuridicidad del comportamiento, lo opuesto al ordenamiento jurídico; y cuando arremete contra el bien jurídico familia, en este caso se constata la acción típica bigamia que se califica luego como antijurídica (injusto).

\section{II.1.6. Responsabilidad}

La responsabilidad que comprende a la culpabilidad y prevención, propone la vinculación de la dogmática jurídico penal con la finalidad político criminal, logrando así incluir las consecuencias externas al sistema del derecho penal. En esta categoría se requiere que el bígamo sea imputable, conozca la antijuridicidad del hecho cometido y que le sea exigible comportarse de manera distinta al tipo penal que comentamos.

\section{II.1.7. Tipo de perfecta realización}

Este delito se consuma cuando la persona casada contrae nuevas nupcias; es irrelevante si cohabitan.

\section{II.1.8. Tipo de imperfecta realización}

Se admite la tentativa.

\section{II.1.9. Autoría y participación}

Existe autoría directa, si ambos contrayentes ya eran casados. En el delito in examine son partícipes los padres que hayan inducido al matrimonio conociendo la cualidad de casado de uno de los cónyuges, impulsando al cónyuge libre a contraer las nupcias criminales, debe responder como correo, doctrina que no es generalmente admitida, estimándose más bien 
que estos, así como los que excitan o facilitan la resolución de cometer el delito, dando instrucciones o suministrando los medios para tal fin, habrán de ser incriminados como cómplices. ${ }^{8}$ Estas indicaciones aparecen claras respecto a los testigos de la unión bígama, indudables cómplices.

\section{II.1.10. Circunstancia agravante}

Este delito se agrava de manera específica cuando el agente le hace creer al sujeto pasivo la existencia de un falso estado civil de soltero, viudo o divorciado, por ejemplo: presenta un documento falso en el que indique no estar impedido para casarse. También se agrava de forma genérica si es reincidente, habitual o funcionario público.

\section{II.1.11. Cuestiones procesales}

El delito cometido de bigamia se tramita en el proceso penal común. En el caso de que exista una demanda por nulidad del matrimonio anterior, el interesado deberá plantear un medio técnico de defensa, como la cuestión prejudicial, con la finalidad de suspender la investigación preparatoria hasta que la vía extrapenal emita resolución firme. En el caso de que se condene al contrayente por bigamia, y este luego presente demanda de nulidad del matrimonio anterior y resuelto con resolución firme a su favor, puede interponer en la vía penal, acción de revisión que es una excepción al principio de cosa juzgada.

\section{II.2. Conocimiento del impedimento por el cónyuge libre}

\section{II.2.1 Descripción típica}

Art.140.- El no casado que, a sabiendas, contrae matrimonio con persona casada será reprimido con pena privativa de libertad no menor de uno ni mayor de tres años.

\section{II.2.2. Bien jurídico tutelado}

Es la familia.

\section{II.2.3. Tipo objetivo}

El sujeto activo es la persona soltera, viuda o divorciada que contrae nupcias con el bígamo. El sujeto pasivo es la colectividad, siendo el afectado la persona casada con el bígamo.

La conducta típica consiste en que el no casado contrae matrimonio con una persona casada.

\section{II.2.4. Tipo subjetivo}

Es doloso, y a sabiendas de que su pareja estaba casada, en tal sentido se excluye la forma culposa.

8 Miguel de Carmona, La bigamia (Barcelona: DUX Ediciones y Publicaciones S. A., s/f.), 250. 


\section{II.2.5. Antijuridicidad}

Se entiende por antijuridicidad del comportamiento, lo opuesto al ordenamiento jurídico (antijuridicidad formal); y cuando arremete contra el bien jurídico familia (antijuridicidad material).

\section{II.2.6. Responsabilidad}

La responsabilidad que comprende a la culpabilidad y prevención, propone la vinculación de la dogmática jurídico penal con la finalidad político criminal, pues se requiere que el no casado sea imputable, conozca la antijuridicidad del hecho cometido y que le sea exigible comportarse de manera distinta al tipo penal que comentamos.

\section{II.2.7. Tipo de perfecta realización}

Este delito se consuma cuando se contrae matrimonio.

\section{II.2.8. Tipo de imperfecta realización}

Se admite la tentativa.

\section{II.3. Autorización ilegal de matrimonio por funcionario publico}

\section{II:3.1. Descripción típica}

Art. 141. El funcionario público que, a sabiendas, celebra un matrimonio ilegal será reprimido con pena privativa de libertad no menor de dos ni mayor de cinco años e inhabilitación de dos a tres años conforme al articulo 36, incisos 1,2 y 3.

Si el funcionario público obra por culpa, la pena será de inhabilitación no mayor de un año conforme al artículo 36, incisos 1, 2 y 3.

\section{II.3.2. Bien jurídico tutelado}

Es la familia.

\section{II.3.3. Tipo objetivo}

El sujeto activo es el funcionario público (tipo especial propio). El sujeto pasivo es la colectividad, y los afectados son el cónyuge del matrimonio anterior, o la persona soltera, viuda o divorciada que contrae nupcias, sin saber el estado civil de casado que tenía su pareja.

La conducta típica consiste en celebrar un matrimonio no legal por el alcalde. También, el párroco u ordinario celebrarán el matrimonio por delegación del alcalde. El comité especial encargado de celebrar el matrimonio estará incurso en el tipo in examine, siempre que apreciemos a la comunidad campesina y nativa. Igualmente, es el caso del jefe de registro civil en las capitales de provincia. 


\section{II.3.4. Tipo subjetivo}

Es doloso y "a sabiendas" que ambos contrayentes estaban casados; o uno de ellos, estaba impedido de contraer nupcias. También admite la forma culposa. Si los contrayentes presentan documentación falsa, el intraneus queda excluido del tipo subjetivo.

\section{II.3.5. Antijuridicidad}

Se entiende por antijuridicidad del comportamiento, lo opuesto al ordenamiento jurídico; y cuando arremete contra el bien jurídico familia.

\section{II.3.6. Responsabilidad}

La responsabilidad requiere que el funcionario público sea imputable, conozca la antijuridicidad del hecho cometido y que le sea exigible comportarse de manera distinta al tipo penal que comentamos.

\section{II.3.7. Tipo de perfecta realización}

Este delito se consuma con la celebración del matrimonio.

\section{II.3.8. Tipo de imperfecta realización}

Es posible la tentativa en el primer párrafo del delito in examine, pues en la forma culposa es inadmisible la tentativa.

\section{II.3.9. Concurso}

El tipo materia de análisis entra en concurso ideal con el delito de abuso de autoridad preceptuado en el Art. 376 del Código Penal.

\section{II.4. Inobservancia de las formalidades por funcionario público}

\section{II.4.1. Descripción típica}

Art. 142. El funcionario público, párroco u ordinario que procede a la celebración del matrimonio sin observar las formalidades exigidas por la ley, aunque el matrimonio no sea anulado, será reprimido con pena privativa de la libertad no mayor de tres años e inhabilitación de uno a dos años, conforme al art. 36, incisos 1, 2 y 3.

\section{II.4.2. Bien jurídico tutelado}

Es la familia, particularmente las formalidades del matrimonio.

\section{II.4.3. Tipo objetivo}

El sujeto activo es el funcionario público, párroco u ordinario (tipo especial propio). El sujeto pasivo es la colectividad. 
La conducta típica consiste en celebrar un matrimonio sin observar las formalidades legales, como, por ejemplo, casarse sin testigos. A diferencia del Art. 141 del Código Penal, donde se aprecia que la finalidad perseguida por el agente es permitir que se cometa bigamia por uno o ambos contrayentes. Si los contrayentes son del mismo sexo, estaremos frente a una causa de atipicidad.

\section{II.4.4. Tipo subjetivo}

Es el dolo, y no se requiere elemento subjetivo diverso al dolo. Si los contrayentes presentan documentación falsa, el intraneus queda excluido del tipo subjetivo.

\section{II.4.5. Antijuridicidad}

Se entiende por antijuridicidad del comportamiento, lo opuesto al ordenamiento jurídico; y cuando arremete contra el bien jurídico familia, específicamente las formalidades del matrimonio que se califica luego como antijurídica (injusto).

\section{II.4.6. Responsabilidad}

La responsabilidad comprende a la culpabilidad y prevención, pues se requiere que el funcionario público, párroco u ordinario sea imputable, conozca la antijuridicidad del hecho cometido y que le sea exigible comportarse de manera distinta al tipo penal que comentamos.

\section{II.4.7. Tipo de perfecta realización}

Este delito se consuma cuando se firma el acta del matrimonio celebrado.

\section{II.4.8. Tipo de imperfecta realización}

Es posible la tentativa.

\section{DELITOS CONTRA EL ESTADO CIVIL}

\section{III.1. Supresión o alteración del estado civil}

\section{III.1.1. Descripción típica}

Art. 143. El que, con perjuicio ajeno, altera o suprime el estado civil de otra persona será reprimido con pena privativa de libertad no mayor de dos años o con prestación de servicio comunitario de veinte a cincuenta y dos jornadas.

\section{III.1.2. Bien jurídico tutelado}

Es el estado civil de la persona.

\section{III.1.3. Tipo objetivo}

El sujeto activo es cualquiera (tipo común). El sujeto pasivo es el de mayor edad (tipo común), si fuera menor de edad se aplicará por especialidad el Art. 145 del Código Penal. 
La conducta típica consiste en variar el estado civil real por uno que no corresponde, o hacer imposible que se acredite el estado civil de otra persona.

\section{III.1.4. Tipo subjetivo}

Es doloso, y no se requiere elemento subjetivo diverso al dolo.

\section{III.1.5. Antijuridicidad}

Se entiende por antijuridicidad del comportamiento, lo opuesto al ordenamiento jurídico; y cuando arremete contra el estado civil de la persona que se califica luego como antijurídica.

\section{III.1.6. Responsabilidad}

La responsabilidad que comprende a la culpabilidad y prevención, propone la vinculación de la dogmática jurídico penal con la finalidad político criminal, pues se requiere que el agente sea imputable, conozca la antijuridicidad del hecho cometido y que le sea exigible comportarse de manera distinta al tipo penal que comentamos.

\section{III.1.7. Tipo de perfecta realización}

Este delito se consuma cuando se altera o suprime el estado civil.

\section{III.1.8. Tipo de imperfecta realización}

Se admite la tentativa.

\section{III.1.9. Condición objetiva de punibilidad}

Para la punibilidad de este delito, no basta con que el hecho sea típico, antijurídico y responsable, pues se exige un perjuicio ajeno; en caso contrario, no se castigará el hecho, pues si el sujeto obra por un móvil altruista, será una causa de atipicidad.

\section{III.2. Fingimiento de estado de gravidez o parto}

\section{III.2.1. Descripción típica}

Art. 144. La mujer que finge embarazo o parto, para dar a un supuesto hijo derechos que no le corresponden, será reprimida con pena privativa de la libertad no menor de uno ni mayor de cinco años.

La misma pena privativa de libertad, y además inhabilitación de uno a tres años, conforme al Art. 36, inc. 4, se aplicará al médico u obstetra que cooperen en la ejecución del delito.

\section{III.2.2. Bien jurídico tutelado}

Es el estado civil de la persona. 


\section{III.2.3. Tipo objetivo}

El sujeto activo solo es una mujer, quien es la supuesta madre. El sujeto pasivo es el supuesto hijo, y el afectado considerado padre, así como todos aquellos que tengan un entroncamiento familiar con este.

La conducta típica consiste en manifestar externamente -con palabras o documentos falsos- el fingimiento del embarazo -empleando certificado médico falso- o parto -simula dolores, se asiste por medico u obstetra y presenta un recién nacido- de una criatura viva que no es del sujeto activo, para adquirir un estado civil, dándole automáticamente derechos, como al nombre, apellido, sucesorios, alimentos, etc., que no le corresponde. El tipo no exige que la mujer se encuentre embarazada, y su hijo haya nacido muerto.

\section{III.2.4. Tipo subjetivo}

Es el dolo y la intención de que "la mujer quiera dar a un supuesto hijo derechos que no le corresponden".?

\section{III.2.5. Antijuridicidad}

Se entiende por antijuridicidad del comportamiento, lo opuesto al ordenamiento jurídico (antijuridicidad formal); y cuando arremete contra el bien jurídico estado civil de la persona (antijuridicidad material).

\section{III.2.6. Responsabilidad}

La responsabilidad requiere que la mujer que es la supuesta madre sea imputable, conozca la antijuridicidad del hecho cometido y que le sea exigible comportarse de manera distinta al tipo penal que comentamos.

\section{III.2.7. Tipo de perfecta realización}

Este delito se consuma con el fingimiento del embarazo o parto (delito de mera actividad), sin que sea necesaria la inscripción del supuesto hijo en el Registro Civil.

\section{III.2.8. Autoría y participación}

Existe autoría directa, pues tiene dominio de acción la mujer que finge embarazo o parto. Se consideran partícipes en este delito el médico u obstetra (cómplices primarios) cuando certifiquen el estado de embarazo o el alumbramiento como verdadero, sabiendo que es falso.

9 Luis Bramont Arias, Temas de derecho penal, tomo IV (Lima: SP Editores, 1988), 42. 


\section{III.3. Alteración o supresión de la filiación de menor de edad}

\section{III.3.1. Descripción típica}

Art. 145. El que exponga u oculte a un menor, lo sustituya por otro, le atribuya falsa filiación o emplee cualquier otro medio para alterar o suprimir su filiación será reprimido con pena privativa de la libertad no menor de uno ni mayor de cinco años.

\section{III.3.2. Bien jurídico tutelado}

Es el estado civil de la persona.

\section{III.3.3. Tipo objetivo}

El sujeto activo es cualquiera (tipo común). El sujeto pasivo es el menor de edad, a quien se le da una filiación falsa, para variar o eliminar la anterior.

La conducta prohibida de exponer a un menor de edad implica sacarlo de su ámbito familiar, mientras que ocultar es sustraer a un menor de edad llevándolo a lugar distinto de la vigilancia de los padres, con la finalidad de insertarlo en otra esfera familiar. También, "el comportamiento consistirá como en el caso del Art. 143 del Código Penal, en alterar o suprimir el estado civil del menor, variando el que tiene o eliminando dicho estado. No es exigencia del tipo "el perjuicio de tercero" de donde se entiende que el ilícito se realiza aun en la hipótesis de que fuera en beneficio del menor, dejándose a salvo el eventual estado de necesidad disculpante". ${ }^{10}$ El tipo en comentario, es numerus apertus, en razón de que se puede emplear cualquier otro medio para alterar o suprimir la filiación.

\section{III.3.4. Tipo subjetivo}

Es el dolo. Se admite el error de tipo sobre la identidad del menor de edad, considerando que es otro. El móvil del honor atenúa la punibilidad.

\section{III.3.5. Antijuridicidad}

Se entiende por antijuridicidad del comportamiento, lo opuesto al ordenamiento jurídico; y cuando arremete contra el bien jurídico estado civil de la persona que se califica luego como antijurídica (injusto).

\section{III.3.6. Responsabilidad}

La responsabilidad comprende a la culpabilidad y prevención, pues se requiere que el agente sea imputable, conozca la antijuridicidad del hecho cometido y que le sea exigible comportarse de manera distinta al tipo penal que comentamos.

10 Javier Villa Stein, Derecho penal. Parte especial IB (Lima: Editorial San Marcos, 1998), 85-86. 


\section{III.3.7. Tipo de perfecta realización}

Este delito se consuma cuando se altera o suprime la filiación del menor de edad.

\section{III.3.8. Tipo de imperfecta realización}

Se admite la tentativa.

\section{III.3.9. Condición objetiva de punibilidad}

Para la punibilidad de este delito, no se exige un "perjuicio ajeno", en tal sentido basta que el hecho sea típico, antijurídico y responsable para que se castigue.

III.4. Móvil del honor

\section{III.4.1. Descripción típica}

Art.146. Si el agente de alguno de los delitos previstos en este capitulo comete el hecho por un móvil de honor, la pena será de prestación de servicio comunitario de veinte a treinta jornadas.

\section{III.4.2. Exégesis del tipo}

De acuerdo con este dispositivo se atenúa privilegiadamente la pena al agente cuando comete algunos de los delitos contra el estado civil por un móvil del honor, pues es una facultad impuesta al juzgador por la norma jurídica, y no de libre discrecionalidad; por ejemplo, los abuelos inscriben a su nieto como su hijo, con el fin de proteger el honor de sus hijos (incesto); o cuando el nińo es reconocido por el novio como su hijo, sabiendo que no lo es, pues es producto de una violación sexual sufrida por su prometida.

\section{ATENTADOS CONTRA LA PATRIA POTESTAD}

\section{IV.1. Sustracción de menor de edad}

\section{IV.1.1. Descripción típica}

Art. 147. El que, mediando relación parental, sustrae a un menor de edad o rehísa entregarlo a quien ejerza la patria potestad será reprimido con pena privativa de libertad no mayor de dos años.

La misma pena se aplicará al padre o la madre u otros ascendientes, aun cuando aquellos no hayan sido excluidos judicialmente de la patria potestad.

\section{IV.1.2. Bien jurídico tutelado}

Son los derechos y deberes inherentes a la patria potestad ${ }^{11}$ y la seguridad del menor de edad.

11 Vid Héctor Cornejo Chávez, Derecho familiar peruano, tomo II (Lima: Gaceta Jurídica, 1998), 188. 


\section{IV.1.3. Tipo objetivo}

El sujeto activo es el pariente. Incluyéndose a los padres privados del ejercicio de la patria potestad. También, es autor el padre, la madre y los ascendientes no privados de ejercer la patria potestad. En cuanto a la relación parental, lo entendemos en sentido amplio; porque en el aspecto lingüístico parental no solo comprende a los padres sino también a los parientes, ${ }^{12}$ como lo refiere la Real Academia de la Lengua Espańola; en tal sentido discrepamos con la apreciación de Reyna Alfa ${ }^{13}$ (¿discrepan respecto al primer párrafo?).El sujeto pasivo es el que ejerce la patria potestad (padres y todo aquel que ejerza la patria potestad legalmente) y el menor de edad.

La conducta típica consiste en sustraer por un periodo relevante al menor de edad (Tipo de acción) o rehúsa entregarlo a quien ejerce la patria potestad legalmente sobre el menor de edad (tipo de omisión propia), pero debiendo existir previamente un reclamo del sujeto pasivo, y sabiendo de esto el agente. En este último supuesto, el menor de edad está legalmente con el sujeto activo, pues esto es antes de rehusarse a entregarlo; mientras que en la sustracción no se aprecia esto.

\section{IV.1.4. Tipo subjetivo}

Es doloso, y no se requiere elemento subjetivo diverso al dolo.

\section{IV.1.5. Antijuridicidad}

Se entiende por antijuridicidad del comportamiento, lo opuesto al ordenamiento jurídico (antijuridicidad formal); y cuando arremete contra el bien jurídico derechos y deberes inherentes a la patria potestad y la seguridad del menor de edad (antijuridicidad material).

\section{IV.1.6. Responsabilidad}

La responsabilidad que comprende a la culpabilidad y prevención propone la vinculación de la dogmática jurídico penal con la finalidad político criminal, pues se requiere que el pariente sea imputable, conozca la antijuridicidad del hecho cometido y que le sea exigible comportarse de manera distinta al tipo penal que comentamos.

\section{IV.1.7. Tipo de perfecta realización}

Este delito se consuma en el caso de la sustracción con el desplazamiento del menor, pues es irrelevante que el menor de edad dé su consentimiento para ser trasladado. En cuanto al rehusamiento, este se consuma con la omisión.

$12 \mathrm{Al}$ respecto, vid. Real Academia de la Lengua Española, Diccionario de la lengua española, tomo 14, vigésima segunda edición (Madrid: Espasa Calpe, 2001), 1141.

13 Para una mejor comprensión sobre la polémica, vid. Luis Miguel Reyna Alfaro, Delitos contra la familia (Lima: Gaceta Jurídica, 2004), 113. 


\section{IV.1.8. Tipo de imperfecta realización}

En el caso de la conducta de sustracción se admite la tentativa; mientras que en el comportamiento de rehusamiento resulta inadmisible la tentativa.

\section{IV.1.9. Autoría y participación}

Existe autoría inmediata (pariente que tiene dominio de acción), autoría mediata (pariente que tiene dominio de la voluntad sobre otro) y la coautoría (abuelos que ostentan dominio funcional). Se consideran partícipes en este delito el padre, la madre u otros ascendientes, que aún ostentan la patria potestad, a pesar de estar incursos en un proceso judicial (de suspensión de la patria potestad), sin que se determine por resolución judicial firme la exclusión de esta.

\section{IV.2. Inducción a la fuga de menor de edad}

\section{IV.2.1. Descripción típica}

Art.148. El que induce a un menor de edad a que se fugue de la casa de sus padres o de la de su tutor o persona encargada de su custodia será reprimido con pena privativa de libertad no mayor de dos años o con prestación de servicio comunitario de veinte a cincuenta y dos jornadas.

\section{IV.2.2. Bien jurídico tutelado}

Es la seguridad y libertad ambulatoria del menor de edad, en razón de que se puede entrometer sin dificultad alguna en su capacidad de actuación. ${ }^{14}$

\section{IV.2.3. Tipo objetivo}

El sujeto activo es cualquier persona, es decir, el simple instigador que se vale de cualquier medio psicológico; mas no el partícipe en el hecho punible, pues propiamente "el instigador debe originar en el autor el dolo de cometer el delito". ${ }^{15}$ En esta figura delictiva in examine se entiende que el menor edad no es autor. El sujeto pasivo es el menor de edad y aquel que ejerce la patria potestad o custodia, así como el tutor.

La conducta típica consiste en instigar o inducir a un menor de edad a que se fugue del lugar donde reside; pero si luego el sujeto activo se lleva al sujeto pasivo, estaremos ante una sustracción de menor de edad. La fuga debe ser libremente aceptada y ejecutada por el menor de edad, en caso contrario, el agente cometería delito de coacción, estipulado en el Art. 151 del Código Penal. No habrá instigación si el menor de edad ya estaba decidido a fugarse de la casa de aquel que ejerce la patria potestad o custodia, así como de su tutor.

\section{IV.2.4. Tipo subjetivo}

Es el dolo, y no se requiere elemento subjetivo diverso al dolo.

14 Juan Bustos Ramírez, Manual de derecho penal. Parte especial, tercera edición (Barcelona: Ariel, 1989), 104.

15 Javier Ysrael Momethiano Santiago, Manual de derecho penal. Parte general (Lima: Editorial San Marcos, 2016 ), 400. 


\section{IV.2.5. Antijuridicidad}

Se entiende por antijuridicidad del comportamiento, lo opuesto al ordenamiento jurídico; y cuando arremete contra el bien jurídico seguridad y libertad ambulatoria del menor de edad, que se califica luego como antijurídica (injusto).

\section{IV.2.6. Responsabilidad}

La responsabilidad requiere que el "simple instigador" sea imputable, conozca la antijuridicidad del hecho cometido y que le sea exigible comportarse de manera distinta al tipo penal que comentamos.

\section{IV.2.7. Tipo de perfecta realización}

Este delito se consuma cuando el menor se fuga o trata de fugarse.

\section{IV.3. Participación en pandillaje pernicioso}

\section{IV.3.1. Descripción típica}

Art. 148 A. El que participa en pandillas perniciosas, instiga o induce a menores de edad a participar en ellas, para atentar contra la vida, integridad física, el patrimonio o la libertad sexual de las personas, dañar bienes públicos o privados u ocasionar desmanes que alteren el orden público, será reprimido con pena privativa de libertad no menor de diez ni mayor de veinte años.

La pena será no menor de veinte años cuando el agente:

1. Actúa como cabecilla, lider, dirigente o jefe.

2. Es docente en un centro de educación privado o público.

3. Es funcionario o servidor público.

4. Instigue, induzca o utilice a menores de edad a actuar bajo los efectos de bebidas alcohólicas o drogas.

5. Suministre a menores, armas de fuego, armas blancas, material inflamable, explosivos $u$ objetos contundentes o suministre a los menores. (Modificado por el Decreto Legislativo 1204, ańo 2015. Sin embargo, este decreto ha sido derogado por el Decreto Legislativo 1348, promulgado en el año 2017. Consultar)

\section{IV.3.2. Bien jurídico tutelado}

Es la seguridad y libertad ambulatoria del menor de edad, en razón de que el agente se puede entrometer sin dificultad alguna en su capacidad de actuación. ${ }^{16}$

16 Juan Bustos Ramírez, Manual de derecho penal..., 104. 


\section{IV.3.3. Tipo objetivo}

El sujeto activo es cualquier persona mayor de edad (mero integrante de la pandilla perniciosa) que se vale de cualquier medio psicológico, es decir, es el partícipe en el hecho punible, pues el instigador debe originar en el autor (menor de edad) el dolo de cometer infracciones. También es agente el cabecilla, líder, dirigente, jefe, docente, funcionario o servidor público. El sujeto pasivo es el menor de edad y los que ejercen la patria potestad o custodia, y el tutor.

El comportamiento consiste en instigar o inducir a un menor de edad a participar en una pandilla perniciosa -grupo de adolescentes que se reúnen y actúan para agredir a terceros, lesionando la integridad física de las personas, atentando contra la vida de las personas, vulnerando la libertad sexual de las personas, dańando los bienes públicos o privados u ocasionando desmanes que alteren el orden interno-, para cometer las infracciones, ya sea en calidad de autor o partícipe. No habrá instigación si el menor de edad ya estaba decidido a participar en una pandilla perniciosa. No se admite la instigación en cadena.

\section{IV.3.4. Tipo subjetivo}

Es doloso, y no se requiere elemento subjetivo diverso al dolo.

\section{IV.3.5. Antijuridicidad}

Se entiende por antijuridicidad del comportamiento, lo opuesto al ordenamiento jurídico (antijuridicidad formal); y cuando arremete contra el bien jurídico seguridad y libertad ambulatoria del menor de edad (antijuridicidad material).

\section{IV.3.6. Responsabilidad}

La responsabilidad comprende a la culpabilidad y prevención, pues se requiere que el "partícipe en calidad de instigador, cabecilla, líder, docente, funcionario o servidor público" sea imputable, conozca la antijuridicidad del hecho cometido y que le sea exigible comportarse de manera distinta al tipo penal que comentamos.

\section{IV.3.7. Tipo de perfecta realización}

Para la consumación no es necesario que el menor pertenezca a la pandilla perniciosa, basta con la realización de la conducta descrita.

\section{IV.3.8. Circunstancia agravante}

Este delito se agrava de manera específica cuando el agente es considerado:

- Cabecilla, líder, dirigente o jefe, por tratarse de un derecho penal de autor, pues no se requiere que el sujeto activo instigue a un menor de edad a participar en una pandilla perniciosa. 
- Docente en un centro de educación. El agente debe estar en actividad, y puede enseńar a nivel primaria, secundaria o superior, ya sea en una entidad privada o pública.

- Funcionario o servidor público -en razón a lo previsto en el Art. 425 del Código Penal- que instigue a un menor de edad a participar en una pandilla perniciosa.

- Instigador (partícipe) o emplea a menores de edad (autoría mediata) a actuar (infracciones) bajo los efectos de bebidas alcohólicas o drogas. Si el agente simplemente suministra bebidas alcohólicas a menores de edad, estaremos ante una falta contra las buenas costumbres.

- Mayor de 18 años y emplea armas de fuego, armas blancas, material inflamable, explosivos u objetos contundentes; o proporcione estos a los menores de edad para sus infracciones. En el tipo penal se aprecia la concurrencia del ilícito de tenencia ilegal de armas de fuego y explosivos.

También el tipo se agrava de forma genérica si el sujeto activo es reincidente, o habitual en el delito.

\section{OMISIÓN DE ASISTENCIA FAMILIAR}

\section{V.1. Incumplimiento de obligación alimentaria}

\section{V.1.1. Descripción típica}

Art. 149.- El que omite cumplir su obligación de prestar los alimentos que establece una resolución judicial será reprimido con pena privativa de libertad no mayor de tres años, o con prestación de servicio comunitario de veinte a cincuenta y dos jornadas, sin perjuicio de cumplir el mandato judicial.

Si el agente ha simulado otra obligación de alimentos en connivencia con otra persona o renuncia o abandona maliciosamente su trabajo, la pena será no menor de uno ni mayor de cuatro años.

Si resulta lesión grave o muerte y estas pudieron ser previstas, la pena será no menor de dos ni mayor de cuatro años en caso de lesión grave, y no menor de tres ni mayor de seis años en caso de muerte.

\section{V.1.2. Bien jurídico tutelado}

Es la familia, particularmente la asistencia familiar, es decir los alimentos, ${ }^{17}$ pues "se trata de un interés tutelado por razones de humanidad". ${ }^{18}$

17 Es la asistencia en sentido estricto. Vid. Max Arias-Schreiber Pezet, Exégesis del Código Civil peruano de 1984, tomo VII (Lima: Gaceta Jurídica, 1997), 156.

18 Eloy Momethiano Zumaeta y Max Mallqui Reynoso, Derecho de familia..., 360. 


\section{V.1.3. Tipo objetivo}

El sujeto activo es la persona que se encuentra obligado (cónyuges, ascendientes, descendientes, hermanos, o tutores) a prestar asistencia alimentaria de acuerdo con una resolución judicial por mutuo disenso, divorcio por causal o pensión alimenticia (tipo especial propio). El sujeto pasivo es la persona a la que debe prestarse una pensión alimenticia en virtud de una resolución judicial, sin importar la edad que este tenga. Está incluido el cónyuge afectado por la separación de hecho, y los ascendientes, siempre que se encuentren en estado de necesidad.

La conducta típica consiste en omitir el cumplimiento de la obligación alimentaria establecida por resolución judicial (omisión propia). En tal sentido se exige que previamente se haya llevado a cabo un proceso civil de alimentos. Los actos de incumplimiento del pago de la pensión alimenticia por varios meses se determinarán como un delito continuado.

\section{V.1.4. Tipo subjetivo}

Es el dolo, y no se requiere elemento subjetivo diverso al dolo. En caso de que el agente se encuentre sin capacidad económica, se excluirá el tipo subjetivo.

\section{V.1.5. Antijuridicidad}

Se entiende por antijuridicidad del comportamiento, lo opuesto al ordenamiento jurídico; y cuando arremete contra el bien jurídico familia, específicamente la asistencia familiar. Si el sujeto trata de conservar su subsistencia, estamos ante un estado de necesidad justificante.

\section{V.1.6. Responsabilidad}

La responsabilidad requiere que el agente sea imputable, conozca la antijuridicidad del hecho cometido y que le sea exigible comportarse de manera distinta al tipo penal que comentamos.

\section{V.1.7. Tipo de perfecta realización}

Este delito se consuma cuando el agente omite prestar alimentos, estando debidamente notificado, pues el ilícito penal se verifica con el incumplimiento al requerimiento judicial debido a que se ha mantenido en el tiempo la realización típica, ya que el mero conocimiento de la resolución judicial que ordena una pensión alimenticia y su omisión a esta, invocado por Salinas Siccha, ${ }^{19}$ solo resulta ser la acción que instaura el estado antijurídico. Esto implica que un requisito de procedibilidad como es el requerimiento judicial que fuera formulado al agente coincide con la consumación, más aún si el ilícito es permanente, pero no existe confusión alguna entre estas figuras, pues los entendidos en la materia distinguen lo sustantivo de lo adjetivo.

19 Vid. Ramiro Salinas Siccha, Derecho penal. Parte especial, segunda edición (Lima: Grijley, 2007), 410-411. 


\section{V.1.8. Tipo de imperfecta realización}

No hay tentativa.

\section{V.1.9. Condición objetiva de punibilidad}

Para la punibilidad de este delito, no se exige un "perjuicio efectivo". En tal sentido, basta que el hecho sea típico, antijurídico y responsable, para que se castigue.

\section{V.1.10. Circunstancia agravante}

La pena se agrava cuando el agente ha simulado otra obligación de alimentos en connivencia con otra persona, así como ha renunciado o abandonado maliciosamente su trabajo. También la conducta prohibida incrementará su punibilidad si existió lesión grave o muerte no querida, pero prevista por el agente. Genéricamente, la penalidad aumenta si el sujeto activo es reincidente o habitual.

\section{V.2. Abandono de mujer en estado de gestación}

\section{V.2.1. Descripción típica}

Art. 150. El que abandona a mujer en estado de gestación, a la que ha embarazado y que se halla en situación crítica será reprimido con pena privativa de libertad no menor de seis meses ni mayor de cuatro años y con sesenta a noventa días multa.

\section{V.2.2. Bien jurídico tutelado}

Es la familia, particularmente la asistencia familiar, es decir, el respeto, el apoyo, y los cuidados recíprocos entre cónyuges ${ }^{20}$ (la norma no refiere si la gestante es casada o no).

\section{V.2.3. Tipo objetivo}

El sujeto activo es el varón que ha embarazado al sujeto pasivo, sin que el tipo exija calidad de cónyuge, concubino, novio o amante. El sujeto pasivo es la mujer y el feto, sin que se exija por el tipo un determinado estado civil.

La conducta típica consiste en abandonar -incumplir prestar asistencia-a una mujer en gestación (anidación del óvulo fecundado en la pared uterina), que es embarazada por el agente, estando en riesgo su salud y vida por alejarse totalmente, y no dar apoyo (delito de omisión propia).

\section{V.2.4. Tipo subjetivo}

Es el dolo, y se requiere como elemento subjetivo que el agente conozca con certeza que es el padre. ${ }^{21}$

20 Es la asistencia en sentido amplio, según Max Arias-Schreiber Pezet, Exégesis del Código Civil peruano de $1984 \ldots, 156$.

21 Vid. Alonso Raúl Peña Cabrera Freyre, Derecho penal. Parte especial, tomo I (Lima: Idemsa, 2013), 499-500. 


\section{V.2.5. Antijuridicidad}

Se entiende por antijuridicidad del comportamiento, lo opuesto al ordenamiento jurídico;

y cuando arremete contra el bien jurídico familia, particularmente la asistencia familiar que se califica luego como antijurídica (injusto).

\section{V.2.6. Responsabilidad}

La responsabilidad requiere que el varón que ha embarazado al sujeto pasivo sea imputable, conozca la antijuridicidad del hecho cometido y que le sea exigible comportarse de manera distinta al tipo penal que comentamos.

\section{V.2.7. Tipo de perfecta realización}

Este delito se consuma cuando el varón abandona a la mujer embarazada que se encuentra en situación riesgosa.

\section{CONCLUSIONES}

- La familia no es el único bien jurídico que se protege, pues en el Titulo III, Libro segundo del Código Penal, se resguarda de lege ferenda la institución familiar; y de lege lata se protege por ejemplo: las formalidades del matrimonio (Art. 142 del Código Penal), el estado civil de la persona (Art. 143 del Código Penal), los derechos inherentes a la patria potestad y seguridad del menor de edad (Art. 147 del Código Penal), la seguridad y libertad ambulatoria del menor de edad (Art. 148 del Código Penal) y la asistencia familiar (Art.149 del Código Penal).

- La exégesis de los delitos contra la familia, nos permite analizar la descripción típica de cada hecho punible siguiendo el iter crítico y valorativo, tanto en su dimensión doctrinal como jurisprudencial, apreciando conceptos sociales dominantes, pues hemos meditado en el bien jurídico tutelado, el tipo objetivo, el tipo subjetivo, la antijuridicidad, la responsabilidad, el tipo de perfecta realización, el tipo de imperfecta realización, la condición objetiva de punibilidad, la autoría y participación, la circunstancia agravante, el concurso y las cuestiones procesales.

\section{REFERENCIAS}

- Arias-Schreiber Pezet, Max. Exégesis del Código Civil peruano de 1984. Tomo VII. Lima: Gaceta Jurídica, 1997.

- Bramont Arias, Luis. Temas de derecho penal. Tomo IV. Lima: SP Editores, 1988. 
- Bramont Arias, Luis Alberto y Luis Alberto Bramont Arias Torres. Código Penal anotado. Cuarta edición. Lima: Editorial San Marcos, 2001.

- Bustos Ramírez, Juan. Manual de derecho penal. Parte especial. Tercera edición. Barcelona: Ariel, 1989.

- Cornejo Chávez, Héctor. Derecho familiar peruano. Tomo II. Lima: Gaceta Jurídica, 1998.

- De Carmona, Miguel. La bigamia. Barcelona: DUX Ediciones y Publicaciones S. A., s/f.

- Momethiano Santiago, Javier Ysrael. Código Penal fundamentado. Lima: Editorial San Marcos, 2011.

- Momethiano Santiago, Javier Ysrael. Manual de derecho penal. Parte general. Lima: Editorial San Marcos, 2016.

- Momethiano Zumaeta, Eloy y Max Mallqui Reynoso. Derecho de familia. Tomo I. Lima: Editorial San Marcos, 2002.

- Muñoz Conde, Francisco. Derecho penal. Parte especial. Valencia: Tirant lo Blanch, 1996.

- Peña Cabrera Freyre, Alonso Raúl. Derecho penal. Parte especial. Tomo I. Lima: Idemsa, 2013.

- Peralta Andía, Javier Rolando. Derecho de familia en el Código Civil. Cuarta edición. Lima: Idemsa, 2008.

- Real Academia de la Lengua Española, Diccionario de la lengua española. Tomo 14. Vigésima segunda edición. Madrid: Espasa Calpe, 2001.

- Reyna Alfaro, Luis Miguel. Delitos contra la familia. Lima: Gaceta Jurídica, 2004.

- Rubio Correa, Marcial. Para conocer la Constitución de 1993. Tercera edición. Lima: Fondo Editorial de la Pontificia Universidad Católica del Perú, 2012.

- Salinas Siccha, Ramiro. Derecho penal. Parte especial. Segunda edición. Lima: Grijley, 2007.

- Villa Stein, Javier. Derecho penal. Parte especial IB. Lima: Editorial San Marcos, 1998.

RECIBIDO: $17 / 01 / 2019$

APROBADO: 20/05/2019 


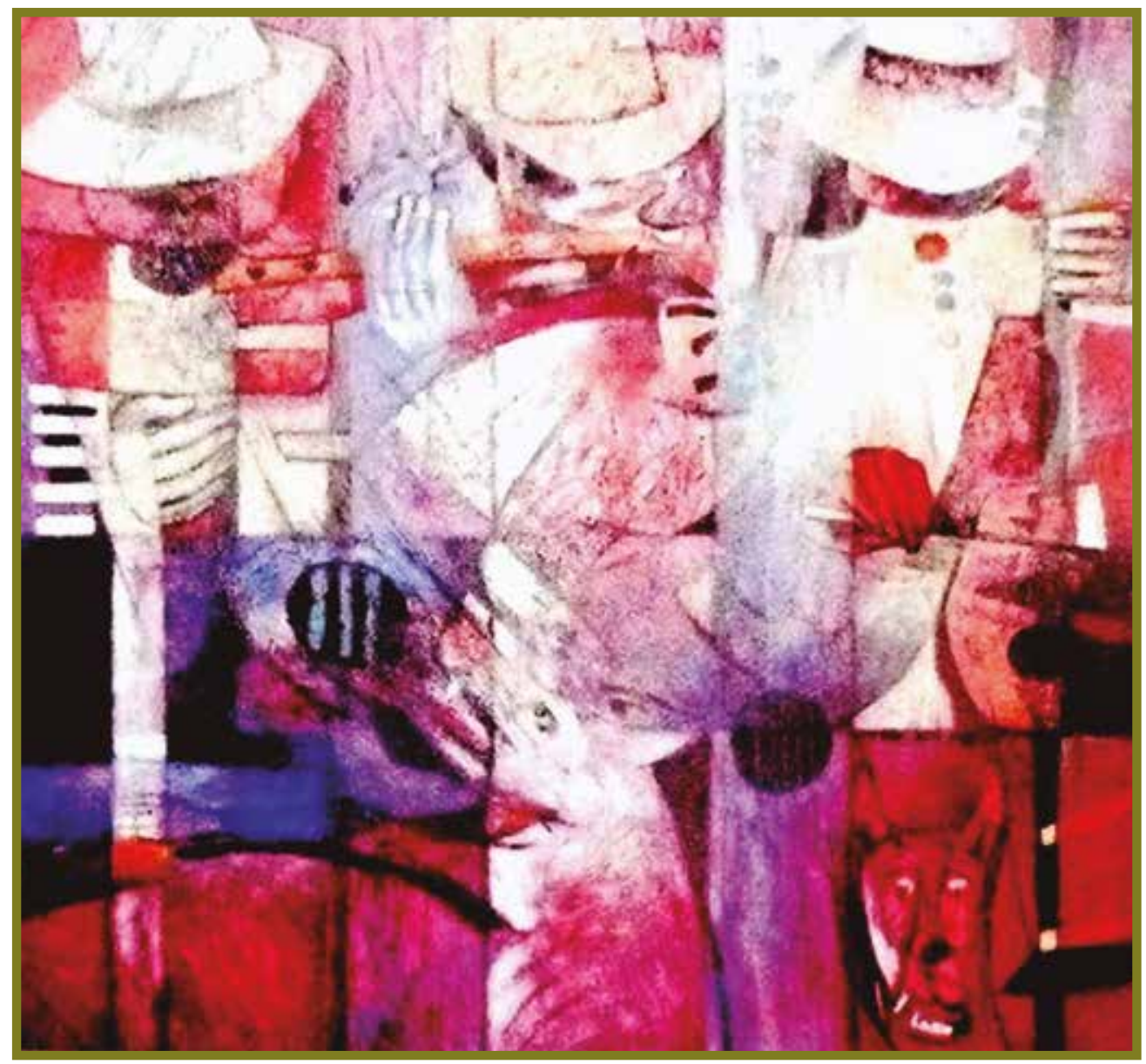

Músicos y perros. Óleo 100 x $110 \mathrm{~cm}$.

Agustín Aquino Mejías (pintor peruano). 